\title{
Correspondence
}

\section{The Mental Health Recovery Star: great for care planning but not as a routine outcome measure}

Dickens et al's paper ${ }^{1}$ reporting on the internal validity of the Mental Health Recovery Star provides evidence for its internal consistency and factor structure. The authors state that it is assessing a single underlying recovery-related construct. However, there is a problem with this statement, since recovery in this context is, by definition, a subjective construct. For this reason, the application of any predetermined constructs (the ten domains of the Recovery Star) can only be considered to be assessing an individual's recovery if those domains happen to coincide with an individual's own priorities. A separate study (currently under review for publication) has investigated the external validity of the Recovery Star and found interrater reliability of nine of the ten domains to be below the generally accepted level (intraclass correlation coefficient $>0.7$ ).

Dickens et al present findings from routinely collected data and suggest these are evidence of the Recovery Star's sensitivity to change in an individual's progress over time (i.e. its responsiveness). The problem is that unless the same member of staff was involved in repeat ratings, these findings are likely to be invalid given the issues with interrater reliability. In addition, responsiveness to change needs to be corroborated by an established measure. Finally, if earlier ratings were discussed between the staff and service user before re-rating (as is encouraged through the training and manual accompanying the Recovery Star), then neutrality is likely to have been reduced, as both may have an investment in showing that progress has been made. One further, fundamental issue is that the 'ladder of change' used to assess progress in each of the ten domains has not been validated psychometrically.

The Recovery Star is very popular and has merit as a tool to enhance discussion of recovery goals between staff and service users. However, although Dickens et al's findings have helped with understanding some of the Recovery Star's psychometric properties, they do not provide evidence for its adoption as a routine outcome measure.

1 Dickens G, Weleminsky J, Onifande Y, Sugarman P. Recovery Star: validating user recovery. Psychiatrist 2012; 36: 45-50.

Helen T. Killaspy, reader and honorary consultant in rehabilitation psychiatry, University College London (UCL), email: h.killaspy@ucl.ac.uk; Jed Boardman, senior policy advisor, Centre for Mental Health; Michael King, director, Mental Health Sciences, UCL Medical School; Tatiana Taylor, research associate, UCL; Geoff Shepherd, recovery programme lead, Centre for Mental Health, London, and visiting professor, Department of Population and Health Services Research, Institute of Psychiatry, London; and Sarah White, biostatistician, St George's, University of London.

doi: $10.1192 /$ pb.36.5.194

Authors' response: Dr Killaspy and colleagues make some important points about the Mental Health Recovery Star, but they adopt a surprisingly dismissive tone about this innovative user-led tool and about our study. With careful caveats, we have argued from naturalistic data that the tool is measuring an underlying construct, and that it has the potential to record reported change. Killaspy et al criticise claims that we simply have not made. Our analysis was not intended to put the psychometric properties of the Mental Health Recovery Star beyond doubt. The development of the tool has employed a user-based approach and, as such, has lacked some of the formal and restrictive academic rigour associated with traditional psychometric testing. We would welcome further research and development to address this.

It is our understanding that the interrater reliability testing cited by the authors is largely based on staff-only ratings of service users' recovery journey. This is not how the tool is intended to be used. It is surprising that Dr Killaspy and colleagues would choose to evaluate a tool in a way which goes against the directions for its use. That intraclass correlation coefficient results fall short of the required 0.7 could reflect the inherent inaccuracy and instability of having sensitive personal recovery dimensions estimated by professionals without discussion with the service user. It is unclear how this fits with recovery as a construct built on individual service users' own priorities. Surely user involvement in the measurement of recovery should be central to the definition of their outcomes.

In relation to sensitivity, it is true that there is a lack so far of proven external validity for the Recovery Star. Again, our paper makes no claims about external validity but merely comments on the fact of change between readings and the promise that this holds. We agree that reported changes are small and that the underlying 'ladder of change' model remains untested. However, it is useful to provide a clear and accessible model of change, which is supported by training and the Recovery Star Organisational Guide. Importantly, this instructs that second readings are taken without reference to the first.

We would like to see future versions of the Recovery Star and other recovery tools that are both psychometrically robust and, crucially, of practical use and relevance to mental health service users and their carers. There is little point in adopting a scientific gold standard for tracking recovery outcomes if it eschews the involvement of people in appraising their own recovery.

Geoff Dickens, head of nursing research and research manager, St Andrew's Academic Centre, King's College London, Institute of Psychiatry, Northampton, email: rdnurse@standrew.co.uk; Judy Weleminsky, (previously) chief executive, Yetunde Onifade, (previously) recovery development manager, Mental Health Providers Forum, London; Philip Sugarman, (previously) chief executive officer and medical director, St Andrew's Academic Centre, King's College London, Institute of Psychiatry, Northampton.

doi: $10.1192 / p b .36 .5 .194 a$

Psychiatric in-patients and the criminal justice system: are there any downsides?

The paper by Wilson et al highlights the serious issue of in-patient violence. The potential benefits of involving the criminal justice system are well laid out and the suggested 